\title{
Simulated SEED PREDATION REVEALS A VARIETY OF GERMINATION RESPONSES OF NEOTROPICAL RAIN FOREST SPECIES ${ }^{1}$
}

\author{
Mario Vallejo-Marín, ${ }^{2}$ César A. Domínguez, and Rodolfo Dirzo ${ }^{3}$
}

\begin{abstract}
Departamento de Ecología Evolutiva, Instituto de Ecología, Universidad Nacional Autónoma de México, Apartado Postal 70275, Mexico D.F., 04510 Mexico

Seed predation, an omnipresent phenomenon in tropical rain forests, is an important determinant of plant recruitment and forest regeneration. Although seed predation destroys large amounts of the seed crop of numerous tropical species, in many cases individual seed damage is only partial. The extent to which partial seed predation affects the recruitment of new individuals in the population depends on the type and magnitude of alteration of the germination behavior of the damaged seeds. We analyzed the germination dynamics of 11 tropical woody species subject to increasing levels of simulated seed predation (0-10\% seed mass removal). Germination response to seed damage varied considerably among species but could be grouped into four distinct types: (1) complete inability to germinate under damage $\geq 1 \%$, (2) no effect on germination dynamics, (3) reduced germination with increasing damage, and (4) reduced final germination but faster germination with increasing damage. We conclude that partial seed predation is often nonlethal and argue that different responses to predation may represent different proximal mechanisms for coping with partial damage, with potential to shape, in the long run, morphological and physiological adaptations in tropical, large-seeded species.
\end{abstract}

Key words: Los Tuxtlas; nonlethal predation; seed germination; simulated seed predation; tropical rain forest.

Seed predation is an omnipresent phenomenon in both temperate and tropical forests. For some species, damage by seed predators may account for the destruction of up to $100 \%$ of their seed crop in some sites and seasons (e.g., Janzen, 1976) and is high in a large number of species (Dirzo and Domínguez, 1986; Brown and Venable, 1991; Sallabanks and Courtney, 1992). Seed predation may be an important selective force guiding the evolution of seed characteristics (Janzen, 1969, 1976, 1981; Brown and Venable, 1991; Blate et al., 1998; Grubb et al., 1998; Mazer, 1998), as well as a key determinant of population growth and recruitment, ultimately affecting forest dynamics and composition (e.g., Dirzo and Miranda, 1991; Crawley, 1992; Hulme, 1998; Silman et al., 2003).

Although rarely acknowledged, not all predation is necessarily lethal to the individual seed (Steele et al., 1993; Dirzo and Domínguez, 1995). For instance, in large-seeded species, small predators such as insect larvae often consume the attacked seed only partially. Likewise, small rodents frequently eat entire small seeds but remove only parts of large seeds (Mendoza, 2005). When such partial damage does not affect the embryo, predation may be nonlethal, thus allowing successful germination (Dalling et al., 1997; Mack, 1998; Dalling and Harms, 1999; Harms and Dalling, 2000). Whether and in what manner partial seed predation affects plant fitness, species distribution, and/or community composition depends

\footnotetext{
${ }^{1}$ Manuscript received 6 July 2005; revision accepted 2 December 2005.

The authors thank S. Sinaca, R. Pérez Ishiwara, and J. Nuñez-Farfán for field and greenhouse assistance. S. LaDeau and C. Kaiser made valuable comments on earlier versions of the manuscript. This study was partially supported by a CONACYT grant to R.D. and a PROBETEL and a CONACYT grant to M.V.M.

2 Author for correspondence (mv6@duke.edu), present address: Biology Department, Duke University, Durham, NC 27708 USA

3 Present address: Department of Biological Sciences, Stanford University, Stanford, CA 94305 USA
}

on the effects of nonlethal damage on seed germination and survival.

The limited data available on the consequences of partial seed predation suggest that its effects range from tolerance of high levels of damage to complete lethality. Dalling et al. (1997) showed that removal of up to $60 \%$ of seed biomass had no effect on the probability of germination in Prioria copaifera Griseb. Tolerance to partial damage caused by simulating insect attacks has been shown for other tropical species including Phaseolus spp. (Cipollini and Stiles, 1991), Gustavia superba (H.B.K.) Berg. (Dalling and Harms, 1999), and Attalea butyraceae (Mutis ex L. f.) Wess. Boer (Harms and Dalling, 2000) and is commonly attributed to the presence of abundant reserves (i.e., large seed sizes) (Dalling et al., 1997; Mack, 1998). In contrast, increasing removal of seed biomass (up to $10 \%$ ) in Mucuna holtonii (Kuntze) Mold. (= M. andreana Micheli) reduced both germination and seedling survival (Janzen, 1976). In addition to reducing germination, partial seed damage may also decrease or eliminate seed dormancy (Hallevy, 1974; Karban and Lowenberg, 1992; Koptur, 1998; Ceballos et al., 2002). Such faster germination may minimize larval damage to seed resources prior to seedling emergence (Karban and Lowenberg, 1992). Finally, partial predation may indirectly result in seed death if, for instance, the attack facilitates the entrance of pathogens (Ceballos et al., 2002).

In this study we assessed the impact of a range of levels of partial seed predation (i.e., seed damage that does not affect the embryo) on germination and seedling survival of 11 woody species from a Mexican tropical rain forest. The species analyzed here are a haphazard sample of woody plants commonly found in mature forest and are characterized by having relatively large seeds (volume from 39 to $22525 \mathrm{~mm}^{3}$ ). Such seeds regularly experience varying levels of seed predation under natural conditions in our study site (see Materials and Methods). To identify differences in the response to predation among species we (1) described the general germination characteristics of each of the species, including the proportion 
of germinated seeds, the germination rate, the time required to start germination (dormancy), and the probability of seedling establishment (i.e., seedling survival at the end of the study) and (2) evaluated the effect of partial seed predation on the germination characteristics and subsequent seedling survival.

The present study was carried out in the vicinity of the Estación de Biología Tropical Los Tuxtlas, in Veracruz, Mexico. This area is almost entirely covered by tropical rain forest with a canopy height ranging from 25 to $35 \mathrm{~m}$. The flora of the zone includes 943 species in 137 families (IbarraManríquez et al., 1997). The most speciose families in the mature forest are the Leguminosae, Moraceae, and Lauraceae (all of them represented in the sampled species of this study). Lianas are a common feature of the vegetation. In the understory, Rubiaceae are predominant and palms are represented by few species but occur in high densities (Bongers et al., 1988). Levels of natural seed predation (percentage of attacked seed crop) are comparable to those of other tropical rain forests (Dirzo, 1987). Typical seed predators of the largeseeded species from this forest include small mammals, birds, and a wide variety of insects.

\section{MATERIALS AND METHODS}

Species in this study were selected according to three main criteria: (1) each species had to have relatively large seeds; (2) the species should complete the life cycle within the mature forest (i.e., no pioneer, gap-colonizing species were included; these are generally small seeded); and (3) seeds had to be abundant enough for the desired treatments and replication (see Artificial predation experiments). The final sample included 11 woody species from 10 families and three life forms: trees (nine species), one treelet (2-5 m high), and one liana. Characteristics of these species, including flowering, fruiting, seed storage behavior, and seed sizes, are summarized in Table 1 . In all but one of the species studied, seed predation is common and with observed values of damage per seed that may reach up to $50 \%$ of seed mass (R. Dirzo, unpublished data) In Cymbopetalum bailloni R.E. Fr., damage is less commonly observed than in the rest of the species. Varying numbers of intact seeds are commonly observed in all species; the experimental treatments of simulated seed predation described below therefore represent events that occur naturally in the field.

Seed collection-Seeds of all selected species were collected according to the following procedure. Seeds were obtained from ripe fruits during each species' fruiting season (see Table 1). Fruits were sampled from several sectors of the crown of 10-20 trees per species. Seeds were extracted by hand from ripe fruits. Viability was estimated by a flotation technique, consisting in placing the seeds in a water-filled container. Viable seeds sunk while empty or damaged seeds floated and were discarded. The reliability of this test was assessed by dissecting seeds of both types and confirming their condition (R. Dizo, unpublished data). This procedure allowed us to use only viable, healthy seeds for the experiments. Viable seeds were dried under direct sunlight for $1 \mathrm{~h}$, and a sample of between 96 and 400 seeds, depending on the species (a total of 3436 seeds over all 11 species), was assigned to each of four experimental treatments (described next).

Artificial predation experiments - To study the consequences of partial seed predation on the germination and seedling survival of the studied species, three artificial seed predation treatments were applied, consisting of $1 \%, 5 \%$, or $10 \%$ of seed biomass (mostly endosperm but also some of the seed coat) removal. Natural seed predation in the species included in this study is lognormally distributed, and the vast majority of damage does not affect more than $10 \%$ of the seed (C. A. Domínguez and R. Dirzo, personal observation). Because the objective of our study was to explore how natural levels of damage affect both germination and establishment, we restricted our treatments of partial seed-predation to a maximum of $10 \%$ biomass removal. In addition to the predation treatments, a control consisting of undamaged seeds was also included. Each seed was individually weighed to calculate the amount of mass needed to be removed according to the treatment. The tissue was removed by drilling a hole opposite to the location of the embryo. The number of seeds assigned to each treatment and the number of replicates (trays) per treatment for each species are shown in Table 1.

Upon treatment, seeds were sown in plastic trays containing forest soil, and trays were irrigated once. Each tray contained seeds of a single species and constituted a replicate (see Table 1). All trays were kept in a fine-mesh enclosure located in mature forest understory. The position of each tray within the enclosure was randomly assigned to avoid position effects. During periodic censuses, the numbers of germinated seeds (determined by radicle emergence) and of surviving seedlings were recorded. Two to seven censuses, depending on the species, were carried out over a 2 years (February 1984-January 1986).

Statistical analyses of germination dynamics-Three parameters were used to define germination dynamics in each species: (1) the maximum proportion of germinated seeds at the end of the experiment, $K$, (2) the germination rate (the number of germinated seeds per unit time), $r$, and (3) the presence and length of dormancy (the time elapsed from sowing to germination of the first seeds). The first two parameters, $K$ and $r$, were obtained for each species by fitting the cumulative proportion of germination as a function of time using the Verhulst logistic growth model (Krebs, 1978). The logistic model used in the calculation of $K$ and $r$ is the integral form of the logistic growth equation:

$$
p=\frac{K}{1+e^{a-r t}},
$$

where $p$ is the proportion of seeds that germinate, $K$ is the maximum

TABLE 1. Growth form, life history strategy, phenology, seed size, and number of seeds of the species used in the control and each of the artificial predation experiments of 11 woody tropical species in Los Tuxtlas rain forest, Veracruz. Sources: Ibarra-Manríquez (1985; 1996a; 1996b); IbarraManríquez and Sinaca (1995); Popma and Bongers (1988); R. Dirzo (unpublished data); A. Orozco-Segovia (Universidad Nacional Autónoma de México, personal communication).

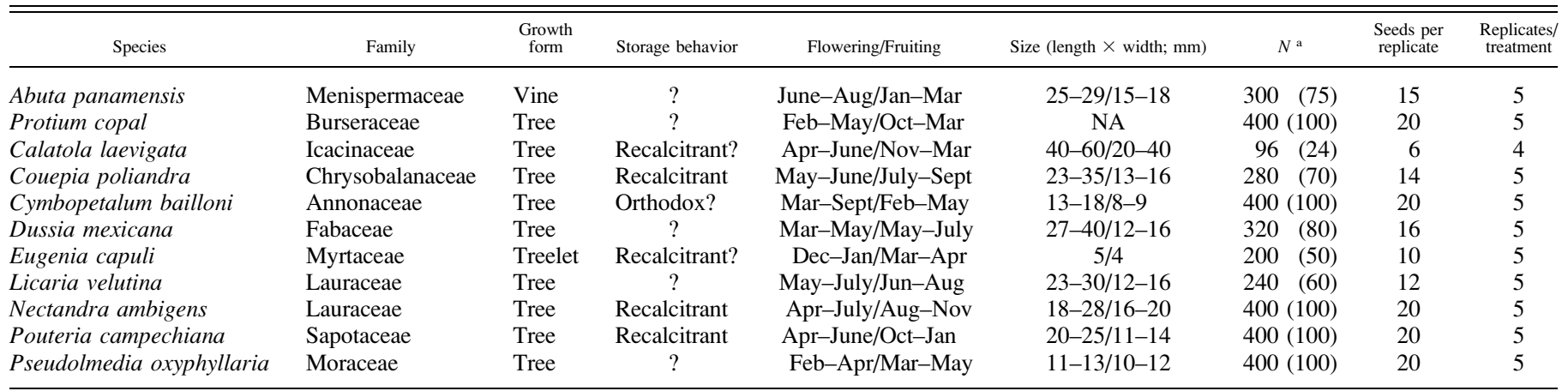

${ }^{a} N$ represents the total number of seeds per species; in parentheses is shown the number of seeds used per treatment (control, 1,5 and $10 \%$ seed mass removal). 
cumulative proportion of germinated seeds, $r$ the instantaneous germination rate, $t$ the time in months, and $e$ and $a$ the base of natural logarithms and an integration constant, respectively. The parameter $K$ is the horizontal asymptote for the observed germination probability, and its value ranges from 0 to 1 . The instantaneous germination rate, $r$, represents the probability of germination per seed per time unit. Mathematically, it corresponds to the slope of the logistic growth curve. The parameter $r$ can be interpreted as an indicator of the temporal homogeneity in seed germination. A relatively low $r$ value indicates relatively high variance in germination time, while relatively high $r$ values (lower variance in germination time) reflect synchronous germination among seeds of a given species. In both these cases, the values are independent of whether seeds from a given species showed any dormancy. The adjustment of experimental data to the logistic model (i.e., the estimation of $K$ and $r$ ) was done using the nonlinear procedure in STATISTICA (version 4.0, StatSoft, Tulsa, Oklahoma, USA). We estimated $K$ and $r$ for the seeds in the control and artificial predation treatments for all 11 species.

Seedling survival - To determine the effects of partial seed damage on seedling survival, the proportion of surviving seedlings in the last census for each species was analyzed using analysis of variance (ANOVA). All data were arcsine square-root transformed to meet the ANOVA assumptions of normality. Statistical analyses for germination and seedling survival were performed in JMP (version 5.1, SAS Institute, Cary, North Carolina, USA).

\section{RESULTS}

Germination characteristics and seedling survival in the control groups-The proportion of germinated seeds, as well as the proportion of surviving seedlings, varied widely among species in the control groups (no biomass removal). Species identity significantly influenced the proportion of germinated seeds $\left(F_{10,43}=4.575, P<0.0002, R^{2}=0.515\right)$. Figure 1 shows the logistic fit to germination data. It is evident that even within the wide range of variation in the germination of a single species, the proportion of variance explained by the models was high $(58-99 \%)$. The values of the maximum proportion of germination $(K)$ estimated from the logistic model ranged from $52.6 \%$ (Calatola laevigata Standl.) to 98.3\% (Licaria velutina van der Werff). Of the 11 species, Pseudolmedia oxyphyllaria Donn. Sm., Protium copal (Schltdl. \& Cham.) Engl., Pouteria campechiana (Kunth) Baehni, Nectandra ambigens (S.F. Blake) C.K. Allen, and Licaria velutina had $K$ values higher than 0.8 (Table 2). In addition, the instantaneous germination rate $(r)$ ranged from 0.722 in Pseudolmedia oxyphyllaria to 25.588 in Licaria velutina (Table 2). The majority of species had a relatively low germination rate ( $r$ ranged from 0.7 to 5 ), thus displaying a relatively high variance in germination time among individual seeds (Table 2). Three other species [Couepia polyandra (Kunth) Rose, Dussia mexicana (Standl.) Harms, and Licaria velutina] presented $r$ values higher than 15 , implying that the germination of all seeds within a given species was completed in a shorter period (i.e., more synchronous germination). Another extremely variable factor among species was the time required to start germination (dormancy). Species like Calatola laevigata required up to 7 mo to germinate, while maximum germination had occurred after only 2 mo in other species (e.g., Licaria velutina, Dussia mexicana; Fig. 1).

Furthermore, the probability of establishment (seedling survival) also showed a wide range of variation among species $\left(F_{10,43}=6.208, P<0.0001, R^{2}=0.590\right)$. In general, the proportion of surviving seedlings at the end of the experimental period was equivalent to the number of germinated seeds (Fig. 2). Therefore, our data suggest that under our experimental conditions germination was the most important event de- termining seedling establishment for all but one of the species. In Cymbopetalum baillonii, in which 56.3\% of its seeds germinated but only half of these survived as seedlings (Fig. 2), factors other than germination may also be important.

Responses to artificial predation-Within each species, the responses to artificial damage ranged from a complete inability to germinate after any level of damage (Protium copal and Calatola laevigata) to an apparent ability to withstand predation (up to $10 \%$ seed mass removal) with no recorded changes in the germination pattern (Nectandra ambigens, Couepia polyandra, Licaria velutina, and Dussia mexicana). Figure 3 shows the changes in the cumulative proportion of germinated seeds induced by the predation treatments for each species. Table 2 shows how these qualitative differences in germination dynamics translated into distinct values of $K$ and $r$.

From these data, we have identified four distinct responses to predation. Each of these response types is characterized by specific changes in $K, r$, and/or the presence of seed dormancy between the control and artificial predation treatments. In the following paragraphs, we briefly describe these four groups (see Fig. 4).

I. Failure to germinate after partial seed-predation-For species in this group (Calatola laevigata and Protium copal), any amount of damage completely prevented germination (Fig. 4A). It is important to note that even though Calatola laevigata had the lowest germination percentage we observed (52.6\%), Protium copal presented relatively high values (87\%), suggesting that seed sensitivity to damage is not explained solely by low $K$ values. Another important difference between these two species was seed dormancy. Protium copal reached its maximum proportion of germinated seeds in the sixth month, while $C$. laevigata started to germinate in the seventh month, reaching its maximum in month 10 .

II. Unchanged germination dynamics-This second group (Nectandra ambigens, Licaria velutina, Couepia polyandra, and Dussia mexicana) is formed by species in which seed predation does not have any measurable effect on germination (Fig. 4B). This group includes more species than any of the other categories described here. The maximum probability of germination in these species varies widely, from 0.6 to 0.98 . In the present group neither $K$ nor $r$ are significantly affected by predation. Species in this group apparently maintain their specific germination characteristics even after loss of up to $10 \%$ of their mass.

III. Reduced germination probability with increasing damage-The third group [Cymbopetalum baillonii, Abuta panamensis (Standl.) Krukoff \& Barneby, and Eugenia capuli (Schltdl. \& Cham.) O. Berg] is characterized by the proportional reduction in the maximum germination probability as the predation level increases (Fig. 4C). In these species, the estimated parameter $K$ reached extremely low values when the artificial predation level was increased to $10 \%$ (e.g., 0.013 in Abuta panamensis). Species in this group had the lowest $K$ values of all species that were capable of germinating after partial predation. In the case of the instantaneous rate of germination, $r$ was first reduced in the $1 \%$ treatment and then increased in the 5\% and 10\% treatments (Table 2). Despite the changes in the absolute values of $r$, the germination curves in the predation treatments are qualitatively similar to the control group except that the maximum germination probability, $K$, is reduced as predation levels increase. 


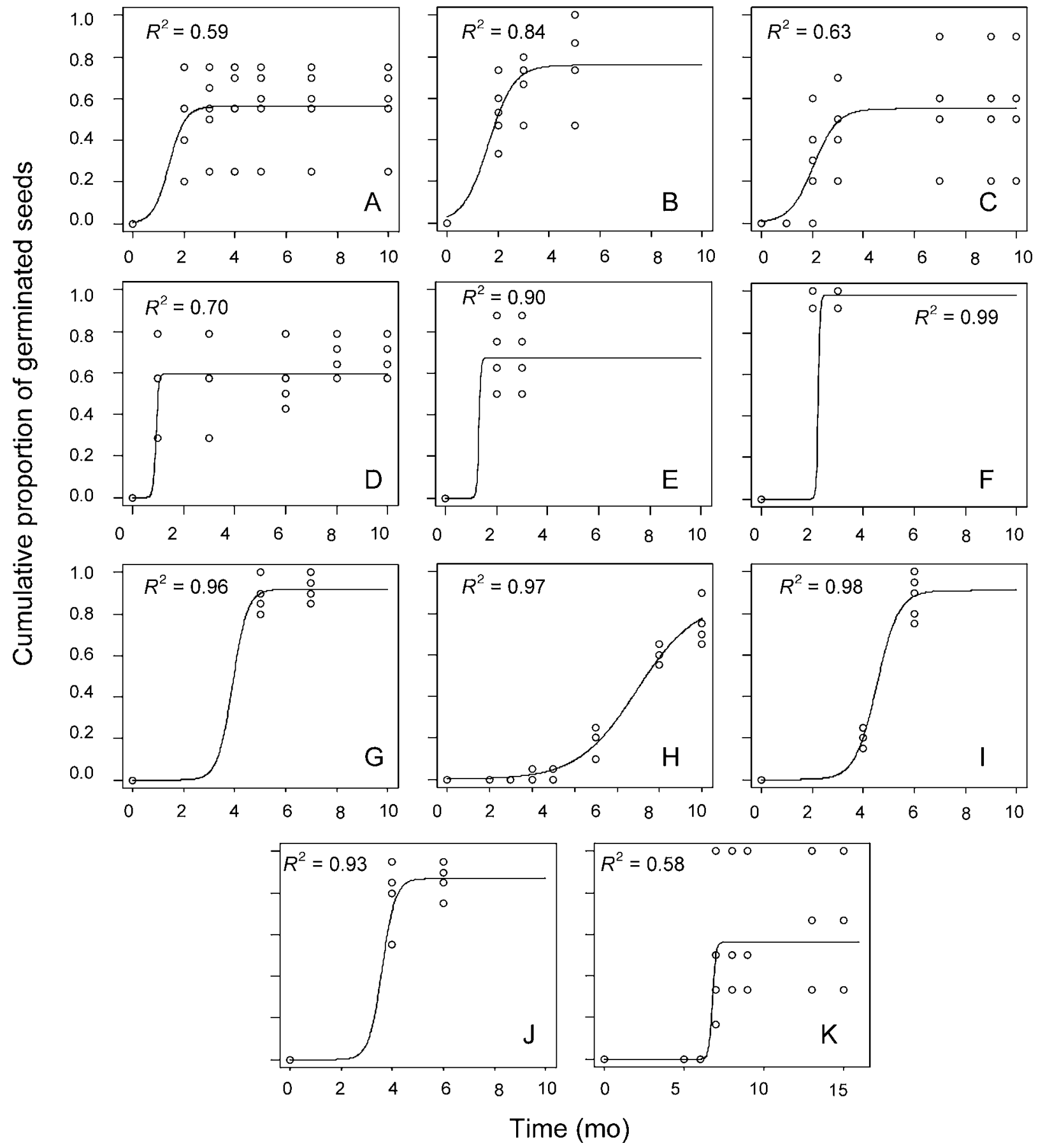

Fig. 1. Germination of 11 tropical woody species from Los Tuxtlas. Data points (open circles) represent the cumulative proportion of germinated seeds in each replicate of the unmanipulated (control) lots. The line depicts the predicted germination proportion estimated from the logistic model (see Materials and Methods: Statistical analyses of germination dynamics). The variance explained by the logistic model $\left(R^{2}\right)$ is given for each species. (A) Cymbopetallum bailloni; (B) Abuta panamensis; (C) Eugenia capuli; (D) Couepia polyandra; (E) Dussia mexicana; (F) Licaria velutina; (G) Nectandra ambigens; (H) Pseudolmedia oxyphylaria; (I) Pouteria campechiana; (J) Protium copal; (K) Calatola laevigata.

IV. Reduced germination probability and change in germination curves-The final group (Pouteria campechiana and Pseudolmedia oxyphyllaria) had relatively high germination probabilities $(K=0.86-0.91)$ and presented the same gradual reduction in $K$ with increasing predation. The largest reduction in $K$ was seen in the $10 \%$ predation treatment (Table 2 ). The characteristic that distinguishes groups III and IV is that in group IV, artificial damage both increased the number of seeds germinating quickly (i.e., higher $r$ values) and reduced the length of dormancy, thus changing the germination curve of the experimental seeds relative to the control (Fig. 4D).

Seedling establishment in the predation treatments-The four patterns of response described for germination were similar to those observed for seedling survival. Species with a gradual 
TABLE 2. Germination probability $(K)$ and germination rate $(r)$ for control and three artificial predation treatments $(1 \%, 5 \%$, and $10 \%$ seed mass removal) in seeds of 11 woody tropical species at Los Tuxtlas, Veracruz. The $1 \%, 5 \%$, and $10 \%$ treatments represent the increasing removal of seed biomass.

\begin{tabular}{|c|c|c|c|c|c|c|c|c|}
\hline \multirow[b]{2}{*}{ Species } & \multicolumn{4}{|c|}{$K$} & \multicolumn{4}{|c|}{$r$} \\
\hline & Control & $1 \%$ & $5 \%$ & $10 \%$ & Control & $1 \%$ & $5 \%$ & $10 \%$ \\
\hline Abuta panamensis & 0.761 & 0.182 & 0.319 & 0.0133 & 2.024 & 1.895 & 2.307 & 183.795 \\
\hline Cymbopetalum bailloni & 0.563 & 0.323 & 0.256 & 0.16 & 3.22 & 2.816 & 5.196 & 823.836 \\
\hline Eugenia capuli & 0.55 & 0.26 & 0.02 & 0.08 & 2.14 & 0.812 & 8.376 & 14.403 \\
\hline Pouteria campechiana & 0.911 & 0.871 & 0.81 & 0.55 & 2.343 & 3.236 & 3.704 & 3.838 \\
\hline Pseudolmedia oxyphyllaria & 0.86 & 0.663 & 0.47 & 0.367 & 0.722 & 1.273 & 1.415 & 1.495 \\
\hline Nectandra ambigens & 0.92 & 0.95 & 0.96 & 0.97 & 3.44 & 3.933 & 3.485 & 4.067 \\
\hline Licaria velutina & 0.983 & 0.983 & 0.883 & 0.883 & 25.588 & 25.378 & 10.07 & 9.763 \\
\hline Couepia poliandra & 0.596 & 0.582 & 0.664 & 0.646 & 17.144 & 17.398 & 17.833 & 16.588 \\
\hline Dussia mexicana & 0.675 & 0.763 & 0.8 & 0.775 & 22.828 & 23.032 & 9.724 & 18.976 \\
\hline Protium copal & 0.87 & 0 & 0 & 0 & 3.891 & 0 & 0 & 0 \\
\hline Calatola laevigata & 0.526 & 0 & 0 & 0 & 9.543 & 0 & 0 & 0 \\
\hline
\end{tabular}

reduction in $K$ with increasing damage also presented a similar reduction in seedling establishment, whereas species with no difference in germination related to seed predation similarly presented no reduction in seedling establishment (data not shown). These results suggest that seed damage does not affect seedling establishment under our experimental conditions.

\section{DISCUSSION}

Germination and establishment in control groups-The present study shows that considerable variation in the germination characteristics of tropical species can be encountered even among plants of a similar life history (long lived, slow growing, and shade tolerant) living within the same habitat (mature forest). In our analysis of 11 tropical woody

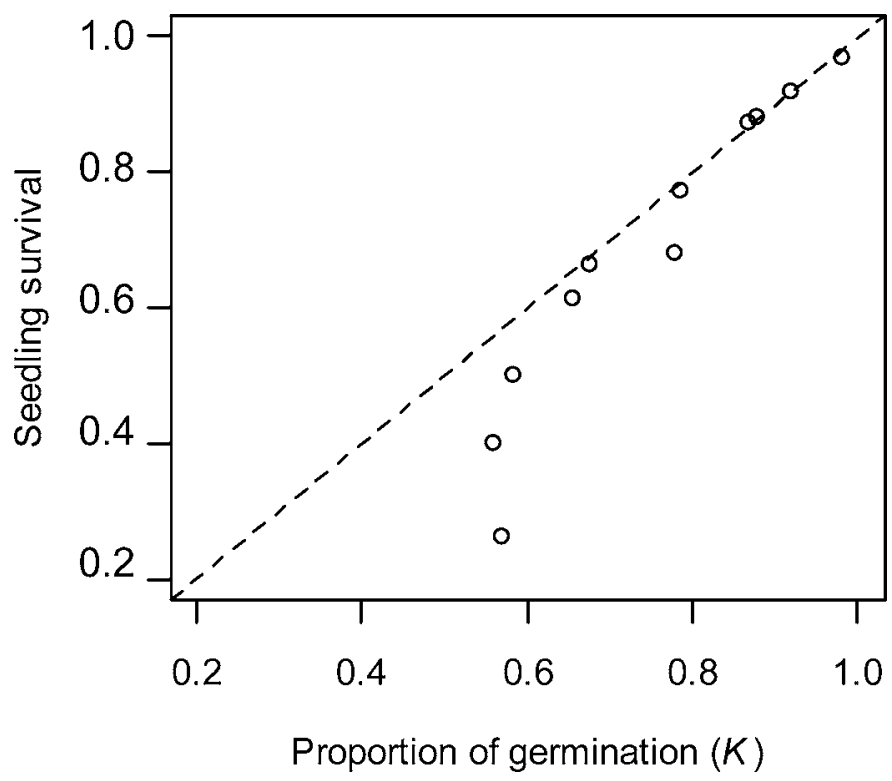

Fig. 2. Seedling survival as a function of seed germination in 11 tropical woody species in Los Tuxtlas, Mexico. Seedling survival represents the average proportion of seeds that germinated and survived until the end of the experiment ( $2 \mathrm{yr}$ ). Proportion of germination $(K)$ is the proportion of seeds that germinated regardless of their later survival. Data shown for control lots only (see Results: Germination characteristics and seedling survival in the control groups). The dashed line represents $100 \%$ survival of seeds that germinate. species of the mature forest, we found that estimates of the maximum probability of germination $(K)$ and instantaneous germination rate $(r)$ varied among species by a factor of 2-110 times, respectively. Furthermore, dormancy varied from a few days to up to $7 \mathrm{mo}$. In contrast, seedling survival after germination was uniformly high for all species. High seedling survival may be a consequence of abundant seed reserves associated with the relatively large seed sizes in all species used in this study (Foster, 1986; Paz and Martínez-Ramos, 2003). Although our experimental design excluded seedling herbivores and probably leaf pathogens (given that pathogenic attack is directly related to insect herbivory in plants from this forest; Garcia-Guzman and Dirzo, 2001), most of the additional variables that should operate in the forest understory were present in our experimental system. Therefore, these results suggest that (in the absence of herbivory) the probability of germination, and not seedling mortality, may be a major determinant of establishment among these 11 species. A subsequent stage in this study should be the analysis of the interactions between partial seed predation and subsequent herbivory on the seedlings emerging from seeds damaged to different degrees (see Janzen, 1976).

Lethality of partial seed predation-For two of the studied species, Calatola laevigata and Protium copal, the removal of as little as $1 \%$ of seed tissue resulted in a complete incapacity to germinate. Although the experimental removal of biomass was done carefully to avoid damage to the embryo, seed mortality could be induced indirectly. Indirect seed mortality could result from pathogens whose entrance is facilitated by perforating the seed coat. In fact, Ceballos et al. (2002) showed that seeds suffering from partial insect damage had higher incidence of mold than undamaged seeds and that high disease rates were associated with decreased seed viability. We, however, did not observe any signs of a pathogen in our artificially damaged seeds. Alternatively, complete seed mortality could result from dehydration during the extraction and manipulation of seeds (A. Orozco-Segovia, Universidad Nacional Autónoma de México, personal communication) or oxidative degradation (Anderson and Baker, 1983). Given that our experimental manipulation was the same for all the species of this study and that only seeds of $C$. laevigata and $P$. copal were completely unviable upon damage, our results suggest the existence of interspecific variation, probably due to the factors described or to other factors, an aspect warranting further investigation. Extreme sensitivity to partial 

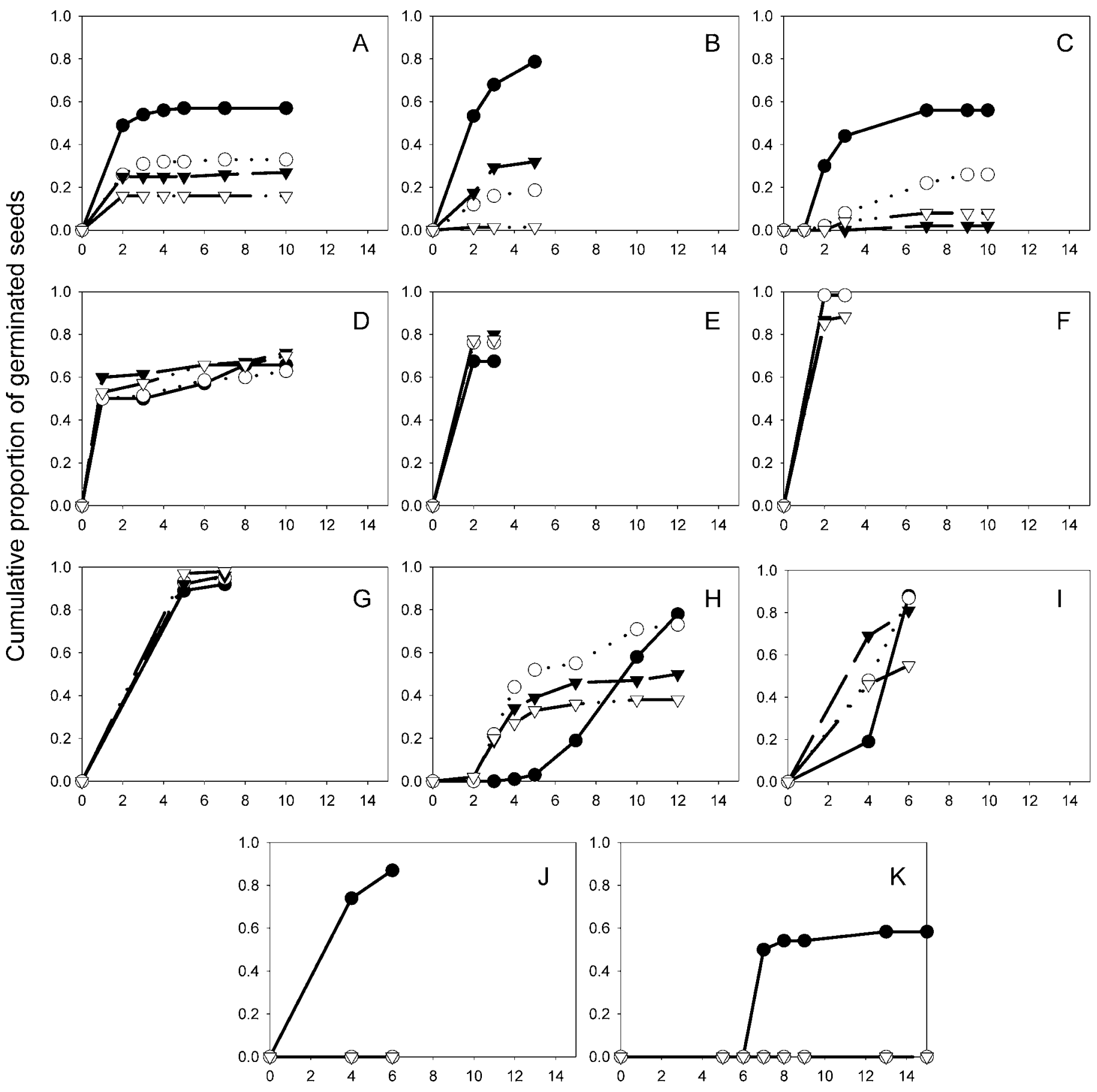

Time (mo)

Fig. 3. Changes in germination dynamics induced by increasing levels of artificial seed damage. Solid circles, control (no seed mass removal); open circles, $1 \%$ seed mass removal; solid triangles, 5\% removal; open triangles, $10 \%$ removal. Data points represent the average for all replicates. Species names as in Fig. 1.

damage may demand mechanisms to avoid seed predation in plants such as these two species. One strategy by which seeds can avoid the detrimental effects of damage is to invest in physical resistance to predators. For instance, the thick, hard seed coats of Calatola laevigata and Protium copal can prevent the damage inflicted by many predators. It is possible that species with heavily armored seeds, such as $C$. laevigata and $P$. copal, rely exclusively on avoidance of damage and lack the physiologic mechanisms to deal with partial predation even of low intensity. By analogy with known antiherbivory mechanisms, these species may have a resistance strategy against herbivores (see Strauss and Agrawal, 1999). 


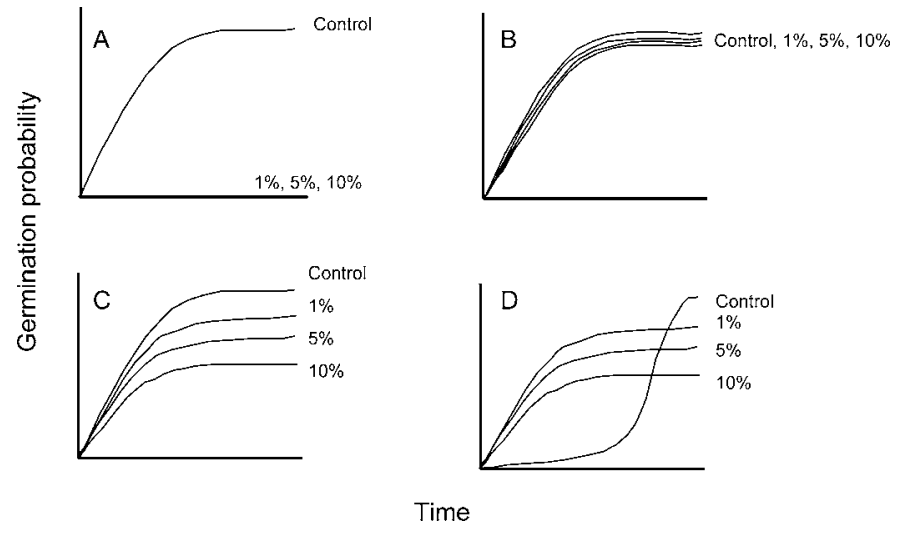

Fig. 4. Four different patterns of germination observed in response to increasing levels $(1,5,10 \%)$ of artificial predation in 11 woody tropical species. (A) Any level of seed damage prevents germination. (B) Different levels of artificial predation have no effect on the germination probability. (C) Increases in artificial predation result in greater reduction of germination. (D) As predation damage increases, progressive reductions in the germination probability result, and resultant change in the germination rate in the treatments in relation to the control.

Nonlethal seed predation-Often, studies on the effects of seed predation on forest dynamics assume that all levels of damage have the same effect on seeds. Usually damaged seeds are considered lost to predators, and seldom is a distinction made between total and partial damage (Ceballos et al., 2002). We have shown that for some species, partial damage does not equate seed mortality. In nine of the 11 species studied, seeds germinated after they were partially damaged. Among the species that can survive partial damage, the responses to predation can be grouped in three categories: (1) unchanged germination dynamics, (2) accelerated germination dynamics, and (3) reduced germination with increasing damage. We propose that these three categories may represent three different proximal mechanisms for coping with nonlethal damage. Next we briefly discuss these responses to non-lethal predation.

(1) Unchanged germination dynamics - A plant defense strategy against herbivory is tolerance, i.e., the ability to grow and reproduce after herbivore damage (Strauss and Agrawal, 1999). Full compensation, or complete tolerance, occurs when herbivory (in this case seed predation) does not reduce individual fitness (Strauss and Agrawal, 1999). A response possibly reflecting a similar, full compensation strategy was exhibited by Nectandra ambigens, Couepia polyandra, Licaria velutina, and Dussia mexicana. In these species, removal of up to $10 \%$ of seed biomass did not affect their germination dynamics. The ability to withstand damage could reflect an adaptation to deal with predation, if in nature these species are commonly subjected to high levels of partial seed damage. Consistent with this expectation, Sánchez-Garduño (1996) found that seeds of one of the species in this group, $N$. ambigens, is subject to frequent and intensive partial seed damage by coleopteran larvae (Bruchidae and Scolitidae). In addition, seeds of D. mexicana are heavily attacked by larvae of unidentified beetles (R. Dirzo, unpublished data). The fact that these species germinate abundantly in the field and, furthermore, are capable of producing high-density seedling carpets (Dirzo and Miranda, 1991) is compatible with our results and interpretation of tolerance. It is important to note, however, that the effects of predation, although absent in the stages of seed germination and seedling establishment, could be reflected into other fitness components, such as seedling size.

(2) Reduced germination with increasing seed damageFive of the 11 species proportionally reduced their maximum seed germination with increasing levels of seed damage (Cymbopetalum bailloni, Abuta panamensis, Eugenia capuli, Pouteria campechiana, and Pseudolmedia oxyphyllaria). We interpret this response to partial damage as a tolerance mechanism against seed predators in which individuals are not able to fully compensate for the inflicted damage (Strauss and Agrawal, 1999). A similar reduction in germination proportion with increasing damage was reported for Mucuna holtonii (Janzen, 1976). Because in our study direct damage of the embryo was avoided in the simulated predation treatments, the effects of increasing biomass removal is restricted to reduction in the available reserves for embryo development (Lord et al., 1995; Dalling and Harms, 1999). In species with reduced germination with increasing damage, higher levels of predation might be equivalent to smaller seeds and thus reduced available reserves for seed development (Janzen, 1976). We thus may predict that in species within this group, intraspecific variation in seed size may affect germination success.

(3) Accelerated germination dynamics-Another mechanism to cope with the effects of predation is to accelerate germination rates after seed damage. For instance, some Gossypium species increase their germination rates dramatically when parasitized. This accelerated germination has been interpreted in some cases as a strategy to outcompete the developing insect larva, thus reducing the levels of damage to the seed (Karban and Lowenberg, 1992). In this study we observed that two species subjected to partial seed predation shortened the time required for germination and increased their germination rates $(r)$. It is possible that reduced dormancy and faster germination observed in some species are an adaptive response to insect predation. However, additional data on the developmental time of seed predators of our species is needed to assess this hypothesis. Alternatively, shorter dormancy in our artificial predation treatments may represent a nonadaptive response to the scarification of the seed coat, necessary to start germination (Janzen, 1981; Armstrong and Westoby, 1993; Vázquez-Yanes and Orozco-Segovia, 1996; Teketay and Granström, 1997). Further studies on the effects of partial predation may help to distinguish between adaptive and nonadaptive hypotheses of reduced dormancy and faster germination rates.

In conclusion, this study shows that partial damage is not necessarily lethal. In turn, partial damage often has subtle but critical consequences in the germination characteristics of a species. The responses to partial seed predation among the taxa studied here resemble typical plant responses to cope with herbivory. These responses include resistance (Calatola laevigata and Protium copal), tolerance with full compensation (Nectandra ambigens, Couepia polyandra, Licaria velutina, and Dussia mexicana), and tolerance by means of partial compensation with (Pouteria campechiana and Pseudolmedia oxyphyllaria) and without (Cymbopetalum bailloni, Abuta panamensis, and Eugenia capuli) changes in their germination characteristics. Future studies should experimentally determine the extent to which these three nonlethal responses to partial predation occur in other taxa or under other natural levels of damage. However, our findings indicate that partial seed predation may be an important ecological factor for tropical seeds with potential to result in morphological and physiolog- 
ical adaptations in large-seeded species for which damage is often sublethal.

\section{LITERATURE CITED}

Anderson, J. D., AND J. E. BAKer. 1983. Deterioration of seeds during aging. Phytopathology 73: 321-325.

Armstrong, D. P., And M. Westoby. 1993. Seedlings from large seeds tolerate defoliation better: a test using phylogenetically independent contrasts. Ecology 74: 1092-1100.

Blate, G. M., D. R. Peart, and M. Leighton. 1998. Post-dispersal predation on isolated seeds: a comparative study of 40 tree species in a southeast Asian rainforest. Oikos 82: 522-538.

Bongers, F. J. J., J. A. M. Popma, J. Meave Del Castillo, and J. CARABIAS. 1988. Structure and floristic composition of the lowland rainforest of Los Tuxtlas, Mexico. Vegetatio 74: 55-80.

Brown, J. S., AND D. L. Venable. 1991. Life-history evolution of seed bank annuals in response to seed predation. Evolutionary Ecology 5: $12-29$.

Ceballos, L., C. Andary, M. Delescluse, M. Gibernau, D. McKey, and M. HossaerT-McKey. 2002. Effects of sublethal attack by a sucking insect, Hyalymenus tarsatus, on Sesbania drumondii seeds: impact on some seed traits related to fitness. Écoscience 9: 28-36.

Cipollini, M. L., and E. W. Stiles. 1991. Seed predation by the bean weevil Acanthoscelides obtectus on Phaseolus species: consequences for seed size, early growth and reproduction. Oikos 60: 205-214.

Crawley, M. J. 1992. Seed predators and plant population dynamics. In M. Fenner [ed.], The ecology of regeneration in plan communities, 157-191. Commonwealth Agricultural Bureau International, Wallingford, UK.

Dalling, J. W., and K. E. Harms. 1999. Damage tolerance and cotyledonary resource use in the tropical tree Gustavia superba. Oikos 85: 257-264.

Dalling, J. W., K. E. Harms, and R. Aizprúa. 1997. Seed damage tolerance and seedling resprouting ability of Prioria copaifera in Panamá. Journal of Tropical Ecology 13: 481-490.

Dirzo, R. 1987. Estudios sobre interacciones planta-herbívoro en Los Tuxtlas, Veracruz. Revista de Biología Tropical 35: 119-131.

Dirzo, R., AND C. A. Domínguez. 1986. Seed shadows, seed predation and the advantages of dispersal. In A. Estrada and T. H. Fleming [eds.], Frugivores and seed dispersal, 237-249. Junk, Dordrecht, Netherlands.

Dirzo, R, AND C. A. Domínguez. 1995. Plant-herbivore interactions in Mesoamerican tropical dry forests. In S. H. Bullock, H. A. Mooney, and E. Medina [eds.], Seasonally dry tropical forests, 304-325. Cambridge University Press, Cambridge, UK.

DiRzo, R., AND A. MIRANDA. 1991. Altered patterns of herbivory and diversity in the forest understory: a case study of the possible consequences of contemporary defaunation. In P. W. Price, P. W. Lewinsohn, G. W. Fernandes, and W. W. Benson [eds.], Plant-animal interactions: evolutionary ecology in tropical and temperate regions, 273-287. John Wiley, New York, New York, USA.

Foster, S. A. 1986. On the adaptive value of large seeds for tropical moist forests: a review and synthesis. Botanical Review 52: 260-299.

García-Guzman, G., and R. Dirzo. 2001. Patterns of leaf-pathogen infection in the understory of a Mexican rain forest: incidence, spatiotemporal variation, and mechanisms of infection. American Journal of Botany 88: 634-645.

Grubb, P. J., D. Metcalfe, E. A. Grubb, and G. D. Jones. 1998. Nitrogenrichness and protection of seeds in Australian tropical rainforest: a test of plant defence. Oikos 82: 467-482.

Hallevy, G. 1974. Effects of gazelles and seed beetles on germination and establishment of Acacia species. Israel Journal of Botany 23: 120-126.

Harms, K. E., AND J. W. Dalling. 2000. A bruchid beetle and a viable seedling from a single diaspore of Attalea butyracea. Journal of Tropical Ecology 16: 319-325.

Hulme, P. E. 1998. Post-dispersal seed predation: consequences for plant demography and evolution. Perspectives in Plant Ecology, Evolution and Systematics 1: 32-46.
IbARRA-MANRíQueZ, G. 1985. Estudios preliminares sobre la floral leñosa de la Estación de Biología Tropical Los Tuxtlas, Veracruz, Mex. B.Sc. thesis, Universidad Nacional Autónoma de México, Mexico City, D.F., Mexico.

IbARRA-MANRíquez, G. 1996a. Lista florística de la estación de Biología Tropical Los Tuxtlas, Veracruz. México. Mimosaceae-Verbenaceae. Revista de Biología Tropical 44: 41-60.

IbARRA-MANRíQuez, G. 1996b. Lista florística de la estación de Biología Tropical Los Tuxtlas, Veracruz, México. Violaceae-Zingiberaceae. Revista de Biología Tropical 44: 427-447.

Ibarra-Manríquez, G., M. Martínez-Ramos, R. Dirzo, and J. Nuñez FARFÁn. 1997. La vegetación. In E. González-Soriano, R. Dirzo R. C. Vogt [eds.], Historia Natural de Los Tuxtlas, 61-82. Universidad Nacional Autónoma de México, Mexico City, D.F., Mexico.

IbarRa-Manríquez, G., and S. Sinaca. 1995. Lista florística de la estación de Biología Tropical Los Tuxtlas, Veracruz. México. Revista de Biología Tropical 43: 75-115.

JANZEN, D. H. 1969. Seed-eaters versus seed size, number, toxicity and dispersal. Evolution 23: 1-27.

JANZEN, D. H. 1976. Reduction of Mucuna andreana (Leguminosae) seedling fitness by artificial seed damage. Ecology 57: 826-828.

JANZEN, D. H. 1981. Digestive seed predation by a Costa Rican baird's tapir. Reproductive Botany 13: 59-63.

Karban, R., And G. Lowenberg. 1992. Feeding by seed bugs and weevils enhances germination of wild Gossypium species. Oecologia 92: 196-200.

KoptuR, S. 1998. Effect of seed damage on germination in the common vetch (Vicia sativa L.). American Midland Naturalist 140: 393-396.

Krebs, C. J. 1978. Ecology. Harper and Row, New York, New York, USA.

Lord, J., M. Westoby, and M. Leishman. 1995. Seed size and phylogeny in six temperate floras: constraints, niche conservationism and adaptation. American Naturalist 146: 349-364.

MACK, A. L. 1998. An advantage of large seed size: tolerating rather than succumbing to seed predators. Biotropica 30: 604-608.

MAZER, S. J. 1998. Rainforest plants protect their investments. Evolution 13: 471-473.

Mendoza, E. 2005. Consecuencias ecológicas de la defaunación en selvas tropicales de México. Ph.D. thesis, Universidad Nacional Autónoma de México, Mexico City, D.F., Mexico.

Paz, H., and M. Martínez-Ramos. 2003. Seed mass and seedling performance within eight species of Psychotria (Rubiaceae). Ecology 84: 439-450.

Popma, J., AND F. Bongers. 1988. The effect of canopy gaps on growth and morphology of seedlings of rain-forest species. Oecologia 75: 625-632.

Sallabanks, R., and S. P. Courtney. 1992. Frugivory, seed predation, and insect-vertebrate interactions. Annual Reviews Entomology 37: $377-400$.

SÁnCHEZ-GARDUÑo, C. M. 1996. Ecología de la depredación pre dispersión en semillas de Nectandra ambigens en Los Tuxtlas. B.Sc. thesis, Universidad Nacional Autónoma de México, Mexico City, D.F., Mexico.

Silman, M. R., J. W. Terborgh, and R. A. Kiltie. 2003. Population regulation of a dominant rain forest tree by a major seed predator. Ecology 84: 431-438.

Steele, M. A., T. Knowles, K. Bridle, And E. L. Simms. 1993. Tannins and partial consumption of acorns: implications for dispersal of oaks by seed predators. American Midland Naturalist 130: 229-238.

Strauss, S. Y., and A. A. Agrawal. 1999. The ecology and evolution of plant tolerance to herbivory. Trends in Ecology and Evolution 14: 179-185.

Teketay, D., And A. Granström. 1997. Germination ecology of forest species from the highlands of Ethiopia. Journal of Tropical Ecology 14: 793-803.

Vázquez-Yanes, C., and A. Orozco-Seggovia. 1996. Physiological ecology of seed dormancy and longevity. In S. S. Mulkey, R. L. Chazdon, and A. P. Smith [eds.], Tropical forest plant ecophysiology, 535-558. Chapman and Hall, New York, New York, USA. 